Chapter 2

\title{
Optimization of Soil Erosion and Flood Control Systems in the Process of Land Consolidation
}

\author{
Miroslav Dumbrovsky and Svatopluk Korsuň \\ Additional information is available at the end of the chapter \\ http://dx.doi.org/10.5772/50327
}

\section{Introduction}

Extreme hydrological phenomena of recent years have highlighted a well-known fact that it is necessary to pay greater attention to the problems of flood-prevention and soil erosion control on a large part of the Czech Republic. Case study areas are the most endangered territories. The case study area was selected as a case study mainly for its natural conditions and high risk of soil degradation and occurrence of flash floods. Relief, geomorphology, the present state of the complex system of soil properties, the types of agricultural farming practices and land use, are all contributing to accelerated soil erosion and runoff with all its negative impacts on the built-up areas.

The main soil degradation problems in the case study area are soil erosion caused by water, soil compaction and decline in organic matter. Soil erosion is fostered by i) soil degrading (intensive) farming practices such as up and down hill conventional tillage and other conventional agricultural operations on arable land, ii) frequent extreme hydrological events, and iii) a decreasing ability of soils for water retention (decline in organic matter and land conversion). Soil compaction is a problem due to intensive conventional farming on arable land (using heavy machinery). The decline in organic matter results from the constant soil erosion process. Main causes of decline in organic matter are conventional farming practices without using manure and other organic matter. Decline in organic matter causes a decrease of natural crop productivity of soil and decreases yield.

Great runoffs occur on these areas and transform into flood waves in watercourses. Forest grounds are also affected, especially in case of unsuitable transport, wood cut and growth make-up. Solving of the problems of territory protection from unfavourable and damaging effects of overland water flow must therefore begin in catchments areas and particularly during any interference with landscape. Appropriate conservation measures are required to 
prevent and reduce runoff and soil degradation resulting from intensive agriculture. The adoption of the most appropriate practices and optimisation the farming conservation system it is necessary to carry out analyses and evaluations of the erosion rate and the basic characteristics of runoff in given sub-catchments. This system of evaluation provides information about erosion and runoff risks plots and serves for decision making regarding soil conservation and flood prevention measures. The success of the system of soil conservation depends on suitable technical assistance and support from responsible state organisations (Ministry of Agriculture and Ministry of Environment), sufficient sources of information as well as the ability and willingness of land users to adopt soil conservation measures. The main motivation for farmers to apply soil conservation measures is the economic motivation through financial subsidies along with penalties for farmers if they fail to comply with the rules of the funding program.

Nevertheless, when introducing a soil erosion control and flood prevention measures in a certain watershed, best management practices are mostly to be able decrease of erosion rate but unable to restrict a surface runoff substantially. For that reason it is necessary to apply a whole system of soil conservation measures. In places with long slopes technical and biotechnical soil erosion control practices (primarily of linear character) are necessary. These technical measures are broad base terraces and channels in case study area. These biotechnical measures together with the implementation of grassed courses of concentrated surface runoff (grassed waterways) create an appropriate network of new hydrolines in the watershed. Biotechnical line elements of soil erosion control serve as permanent barriers or obstacles for water runoff and are designed in order to determine, by their location, the ways of land management. Some technical and biotechnical measures could be suitable regarding their technical feasibility, economic efficiency and environmental effectiveness. The spatially and functionally limited soil-conservation system in a given teritorry offers spaces and lines in which it would be possible to locate territorial systems of ecological stability under certain conditions. Soil conservation and flood prevention practices, connected with territorial systems of ecological stability can be characterized as desirable anthropogenic landscapeforming elements. These would form the appearance of the landscape and significantly enhance natural processes in the region. They create suitable biological conditions in spite of the fact that they mostly do not meet qualitative and dimensional characteristics of biocentres and biocorridors.

Highly fragmented land ownership is prevalent in the area Biotechnical and technical soil conservation measures cannot be applied without respecting property rights. Integral parts of any project of soil erosion control (its basic network) are usually line elements for soil erosion control (broad base terraces and channels etc.), which run across individual owners' fields. Therefore it is necessary to identify every owner and discuss with the project and relevant proposals. The greatest interventions with agricultural landscape are land consolidation which, apart from other less important objectives, are designed to completely eliminate or at least partly limit unfavourable effects of runoff (especially soil erosion) and thus to become one of the most important elements of territory organisation and protection. Therefore it was found suitable to design the system of the soil and water conservation in the process of land consolidation in the Czech Republic. 
Optimal spatial and functional delimitation of soil erosion control practices in the landscape is one of the basic steps in the plan of comprehenshive land consolidation, in addition to the implementation of a new network of field roads and landscape features enhancing ecological stability. Soil erosion control and flood prevention practices are included in the system of public facilities within the framework of the land consolidation process (where property relations are consistently solved).

The definition of land consolidation is from Act No. 139/2002 Coll., on Reparcelling and Land Authorities and amending Act No. 229/1991 Coll., on the Arrangement of Ownership titles to Land and other Agricultural Assets, as amended. The land consolidation processes in case study area have started in 2005.

This procedure gives solutions to the whole area, both from the aspect of a new land and ownership arrangement (Figure 2) and from the aspect of soil conservation and flood prevention and improvement of environment (Figure 1).

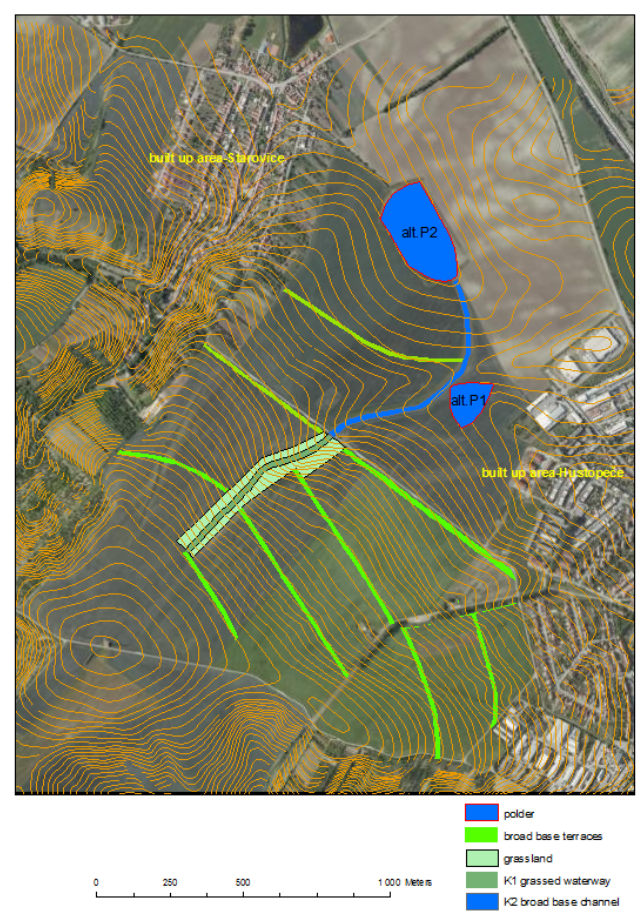

Figure 1. Soil conservation and Flood prevention system. 

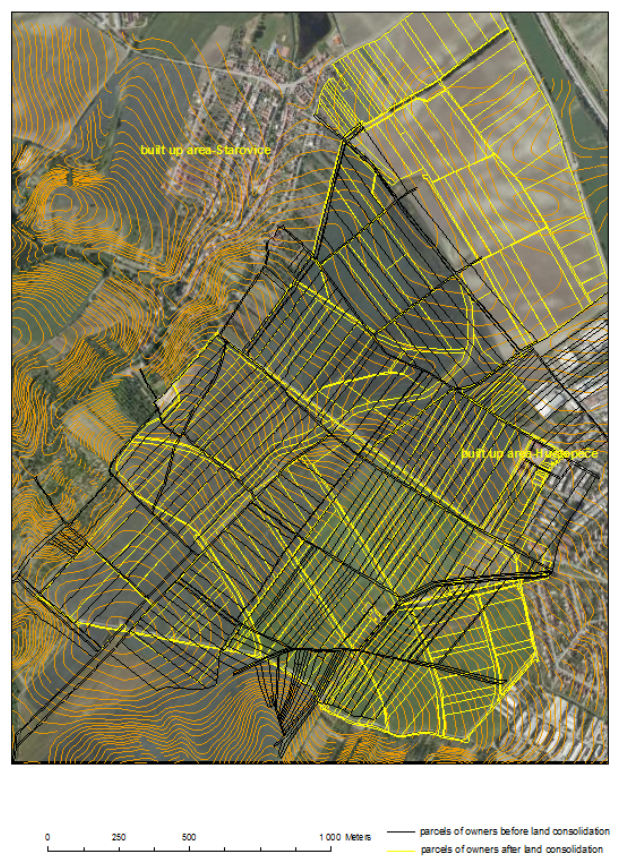

Figure 2. Parcel of owners before and after land consolidation.

Recently, the process of complex land consolidation in the Czech Republic has provided a unique opportunity for improving the quality of the environment and sustainability of crop production through better soil and water conservation. The current process of the land consolidation consists of the rearrangement of plots within a given territory, aimed at establishing the integrated land-use economic units, consistent with the needs of individual land owners and land users.

Integrated territory protection can be reached by controlling runoff by means of design of terraces as a soil erosion control measures. A number of mathematical models, mostly simulation ones, to solve water-management problems have been compiled, some of which include the option of exact mathematical optimization. A certain summary of these models, including their characteristics and application possibilities, were elaborated by Kos (1992). An interesting combination of the application of a simulation and optimization model technique in the elaboration of design of a particular water-management system was described by Major, Lenton et al. (1979), a three-model approach to solve water-management systems was used by Onta, Gupta and Harboe (1991). Benedini (1988) dealt more generally with the design and possible applications of these models. Most likely, an optimization model has not been designed, which would enable to attach territory protection and the measures to eliminate the amount and accumulation of runoff in catchments areas to solving water-management problems. 
The created procedure is a universal tool which can be applied for any territory. It enables to find the most suitable combination of all possible alternatives of various erosion controls and flood protection measures under given conditions of each particular site. Such sites do not always have to be ground used for farming. They may also include in forest or urban areas or site arrays in various territories.

\section{Method}

The optimization process of designing the system of integrated territory protection (the IOU system) begins with the processing of the system of organisational, agrotechnical, biotechnical and technical measures at individual sites of the case study territory. It is necessary to derive hydrograms of direct runoff from extreme rainfall events for each of these variants. Then it is necessary to elaborate the variants of terraces and other conservation measures on all sections of watercourses and variant of designs of retention protection reservoirs. Not only rivers, streams and brooks are included into the watercourse category within this procedure but also sometimes passed watercourses such as terraces, grass infiltration belts or the lines of stabilisation of concentrated runoff waterways in valley lines.

A selection of the most suitable combination of all prepared variants is listed. With respect to the fact that it is necessary to find optimal dimensions for some of the system elements, there is usually a great number, in case of a continual solving even an infinite number, of possible combinations. It is therefore necessary to use an optimalized mathematical model to find the most suitable combination. This model was created on the basis of a mixed discrete programming (Korsuň et al., 2002, Dumbrovský et al., 2006). Its basic building stones are three generally formulated partial models: $A$. partial model of protective measures at individual sites of the case study area. B. partial model of a watercourse. C. partial model of a reservoir.

It is possible to shape an optimization model of integrated territory protection (OMIOU) from these partial models for any particular territory. The partial models are repeatedly inserted into the OMIOU as needed so as to exactly copy the modelled system structure. It is necessary to determine in advance one criterion or more simultaneously operating optimization criteria for each optimization function. A whole range of criteria can be determined for a given purpose. These can be taken from the sphere of economy but also from those of ecology, water-management, social etc. However it is necessary to define the most suitable criteria as far as quality is concerned but also to have a chance to quantify the values of each defined criterion. On top of that, it is necessary, in case of several simultaneously operating optimization criteria, to assign each criterion its adequate weight with which it will enter the solving process and which will support its effect on the result, so called a compromise solution in competition with the other criteria.

In creating the procedure of the IOU system proposal optimization in connection with the process of territory organisation a requirement of a maximal protection of inhabited and other areas with the exertion of minimal means was formulated for the solving process on the level of land consolidation as one of the suitable optimization criteria. It is a criterion 
consisting of three simultaneously operating partial economic, but at the same time watermanagement and socially aimed at their impacts. Criteria include:

- minimization of the average annual damage (material damage: it is estimated that input requirements and conditions will not allow solutions which could lead to losses of human lives) originated by overland runoffs from rainfall events and then by their concentration in watercourses.

- minimization of the average annual economic losses in farming production related to the realisation of proposed protective measures on arable land.

- Minimization of the average annual expenses (the sum of expenses for running and maintenance plus the amortization of the capital goods) of the proposed conservation measures.

Seeing that in most cases they are average annual values, quantified for example in thousands of CZK per year, these criteria can be assigned the same weights 1:1:1 in reflection.

The optimization mathematical model is a system of equations, which model a given system behaviour, the variables in the equation describe a system structure and the dimensions of its individual elements. Non-equations found in each model are transformed into equations by means of additional variables in the course of the model solving process, therefore the term equation is used only. The above mentioned partial models were created in the modelling and calculation system GAMS (General Algebraic Modelling System) in its general form (Charamza, 1993) so it can be used to model any integrated territory protection system. The nature of the solved problems implies that the defining process of all the variables used in the model as positive variables. They can be either continuous ones which are marked $x$ herein after or binary ones (they can take on only 0 or 1 values) marked with the symbol $x_{B}$. Other symbols are used to mark variables and coefficients. Activities proceeding in time must be modelled in the whole system according uniform timekeeping.

The partial model $A$ is aimed at terraces and other biotechnical, agrotechnical, and organisation conservation measures in the catchments area of a certain watercourse. These measures are usually designed within land consolidation to decrease overland flow of rainfall events and thus to limit the effects of soil erosion and damage in inhabited territories. The various proposals of protective measures must be elaborated in each individual case before an optimization model is designed (pre-optimization) as pragmatically created systems of various, mutually complementary interventions with the individual catchments area elements. Such a partial catchments area element could be, for example, valley and slope area above one bank of a certain watercourse section in the range from the bank line to the interstream divide line.

The part of runoff from the design rainfall events which will not be caught by the system of catchments area protective measures (residual runoff) will concentrate in a particular watercourse and will create a design $Q$ runoff or flood wave. The time $T$ of passage of the design flood wave through a watercourse will be divided into $r$ of equally long time intervals (TI); time $t$ of the durance of one TI will thus be given by the relation $t=T / r$. For the individual TIs, partial volumes $w_{1}$ of the design flood wave are then quantified, $i=1,2, \ldots, r$. 
In case of the application of the above mentioned optimization criterion, the following indicators must be quantified for each pre-optimization processed variant of the protective measure set on a partial catchments area element:

- its estimated effect $U$ expressed financially as an average annual level of damage on land, growth, buildings, roads etc. which will occur after the variant has been realised (residual damage),

- estimated average annual economical loss $E$ in farming production related to the realisation of the proposed measures on arable land.

- realisation costs of a particular variant and its average annual own costs $N$,

- the amount of residual runoff $O_{i}$ into a watercourse in the individual TIs.

These data represent input information for the partial model $A$. In the course of the optimization process, only one - optimal - variant with the most suitable indicators will be chosen from thus prepared variants of systems of protective measures for each partial catchments area element. Residual runoffs concentrating in a watercourse runway from the watercourse adjacent partial areas protected by optimal systems of measures will cause a gradual accretion of a flood wave passing through the watercourse. The protection from damage which could be caused by this flood wave will be provided by the protective measures on the watercourse and retention protective reservoirs as mentioned later (the partial models $B$ and $C$ ).

Binary variables can be used for modelling of individual variants of protective measure systems in each of the partial catchments area elements in a discrete way. The total number of catchments area elements will be $m$. If, for example, $n$ variants of protective measure systems of a $d^{\text {th }}$ catchments area element are modelled by relations to binary variables $x_{\text {B1dp }} \in\{0$, $1\}, d=1,2, \ldots, m, p=1,2, \ldots, n$, the effects of these measure systems for this catchments area element can be write into the model using the following equations:

the equation of protective effects (residual damage)

$$
x_{U d}=\sum_{p} U_{d p} \cdot x_{B 1 d p}
$$

the equation of economic damage

$$
x_{E d}=\sum_{p} E_{d p} \cdot x_{B 1 d p}
$$

the equation of own costs

$$
x_{N d}=\sum_{p} N_{d p} \cdot x_{B 1 d p}
$$


the equation of residual runoff, i.e. contribution of a $d^{\text {th }}$ catchments area element to the flood wave volume on a particular watercourse section in $i^{\text {th }} T I$

$$
x_{\text {Oid }}=\sum_{p} O_{i d p} \cdot x_{B 1 d p}
$$

for $i=1,2, \ldots, r$,

$d=1,2, \ldots, m$,

$p=1,2, \ldots, n$,

where $x_{U d}$ is the total residual damage in a $d^{\text {th }}$ catchments area element,

$x_{E, U d}$ is the total economic loss in a $d^{\text {th }}$ catchments area element,

$x_{\text {Oid }}$ is the total residual runoff from a $d^{\text {th }}$ catchments area element in $i^{\text {th }} T I$.

Because only one of the protective measure system variants can enter the solving process, the following condition must be valid for the sum of all the binary variables of a $d^{\text {th }}$ catchments area element:

$$
\sum x_{B 1 d p}=1
$$

The partial model $B$ captures the passage of the design flood wave through the watercourse sections. The sections are either left in their present state, the optimization of a river bed or a contour furrow systems design (including the building of protective dams), or the reconstruction an earlier carried out adjustment or protective dams may be required. A watercourse section can also be a water or dry protective reservoir which will be modelled in a way mentioned in the partial model $\mathrm{C}$ description.

Flood damage that can occur is quantified for each watercourse section during its modelling. Further, runoffs from the section are calculated in the individual TIs of a flood wave passage. With respect to the overland flow from the initial section profile to the last one, it is necessary to determine a time shift which will affect collisions of flood waves on the main watercourse and at the mouths of its tributaries. The mean value of the runoff volume which can be found in a section (in a river bed or also in an inundation territory) in the course of $i$ th $T I$ is at the position of the basic section variable. The values of the other variables are related to this variable: the variables of the water flowing through the section, time of concentration, the level of flood damage in the section, and the level of runoff from the section. The courses of these non-linear functions are derived from the watercourse pre-optimization variant designs. They are replaced with linear function part by part in the optimization model. The formulation of particular equations is mentioned in Chapter 5.1 of Patera, Korsuň et al. (2002). 
The partial model $C$ is outlined for a designed multipurpose water reservoir with unknown capacities of spaces protective controllable $x_{\mathrm{OO}}$, protective non-controllable $x_{\mathrm{ON}}$ and total $x_{V}$. The necessary volumes of the spaces of dead storage $S \geq 0$ and active storage capacity $Z \geq 0$ are constant - these values result from other than protective requirements. The objective of analysis is to find its dimension which, respecting the requirement to create the spaces $S$ and $Z$, with its protective spaces will ensure the reduction of culminated runoff from the reservoir to its optimal level during the passage of the design flood wave. In cases when the designed water reservoir has only a protective function, the value of the $Z$ variable is zero; the values of both variables are zero $S=Z=0$ for a dry protective reservoir.

The unknown volume of the total reservoir space is a variable, whose value which is limited from above by the maximal value $V_{\max }$ corresponding with the biggest realisable variant of the reservoir design during the pre-optimization solutions. From below it is limited by the minimal variant, still acceptable for practice, with the total volume $V_{\min }$.

We cannot forget a situation when building a reservoir will not be acceptable due to the used optimization criteria. It is therefore necessary to introduce a binary variable $x_{B 2} \in\{0,1\}$ into the set of variable values. If this variable has a zero value, the reservoir will not enter the solving process, if $x_{B 2}=1$, the entry of the reservoir into solving is cleared. Then the volume of the total reservoir space (without evaporation and percolation) must correspond with the following conditions

$$
\begin{gathered}
x_{V}=(S+Z) \cdot x_{B 2}+x_{O O}+x_{O N} \\
V_{\min } \cdot x_{B 2} \leq x_{V} \leq V_{m}
\end{gathered}
$$

The equations modelling the passage of the design flood wave through a dam profile, the calculations of the volumes of individual reservoir spaces and of necessary financial means are described in Chapter 5.1 of Patera, Korsuň et al. (2002). The partial model C can be also used for already an existing reservoir with a constant volume of the total space.

The model compilation from the fore mentioned partial elements in the presented form requires the introduction of a set of concrete coefficients and variables into the model for the model equation system to copy completely a particular system of $I O U$. These coefficients and variables should be derived from the pre-optimization processed background materials. In the case of non-standard requirements of an IOU system structure, it is necessary to introduce other equations to the model. Such new equations would capture these requirements. The model solving process in carried out on a computer by means of some of the GAMS system tools. 


\section{Material}

To verify the function and potential of the already described optimization procedure, a system of integrated territory protection was chosen that was proposed within the framework of land consolidation on the case study area between the town of Hustopeče and the village of Starovice in the Czech Republic (see Figure 1). The declining ground in this region is mostly used as arable land. Overland flow is concentrated into its main waterway, which enters the residential parts of Hustopeče. Considerable, and frequently repeating damage, is caused by soil erosion on farm crops, sediment transport from arable land and especially by flooding parts of the town.

The proposed system of integrated protection of this farming territory and town is based on a system of technical-biotechnical, organisational and agrotechnical soil erosion control measures on arable land and of two conservation measures: 1. transfer of concentrated runoff from the drainage furrow or channel $K 1$ in the main valley line over the terrain into the adjacent valley line and creating a channel $K 2$ entering watercourse, 2 . building a dry protective reservoir (polder) $P 1$ to catch parts of runoffs from the main valley line and another polder on the channel K2 in the adjacent valley line above the village of Starovice.

The IOU system design for the given territory is based on the situation which would occur during a rainstorm with hundred-year periodicity (design rainfall). The protective measures with pre-optimization were designed in ten different variants, volume and cost (own costs) functions were derived for both the polders. It is estimated that $P 1$ polder filling, which is a side basin for the channel $K 1$, will proceed through the channel side overfall. For the individual soil erosion control measure alternatives volumes and accumulation of overland runoffs, derived from the design rainfall, in the form of runoff hydrograms from two catchments areas: from the polder $P 1$ catchments and from the polder $P 2$ catchments. The passage of runoff waves through dam profiles of both polders takes from 510 minutes in the alternatives 1 and 2 to 195 minutes in the alternatives 9 and 10. It requires limiting the culmination water passages in the river beds below the two polders: below the $P 1$ this passage (runoff from the P1), which will enter the city sewerage system in Hustopeče, should not exceed $0.125 \mathrm{~m}^{3} \cdot \mathrm{s}^{-1}$, below the $P 2$ the passage limit should be, with regard to the protection of Starovice, chosen at $1.5 \mathrm{~m}^{3} \cdot \mathrm{s}^{-1}$ at most and in variants of 1.0 and $0.5 \mathrm{~m}^{3} \cdot \mathrm{s}^{-1}$ to determine the effect of this passage size on the IOU system optimal solution.

The optimization model consists of 3,506 equations with the total of 1,673 structural variables, 539 of which are binary variables. The model objective function (optimization criterion) minimises the sum of average annual values of flood damages, economic losses and biotechnical measures and polders own expenses in the proportion of 1:1:1. It is ensured that only one protection system alternative can enter the OMIOU optimal solution in both the catchments areas, but it can be different for each of the catchments. These alternatives are marked as $A 1$ and a particular alternative number for the $P 1$ polder catchments, the $P 2$ polder was allocated symbol 2 in a similar way. The polders can enter the solution but they also do not have to. The runoff wave from the $P 1$ polder catchments may be partly or completely trans- 
ferred into the $P 2$ polder. Permissible maximum of water depth in the $P 1$ polder is $5.0 \mathrm{~m}$, it is $4.34 \mathrm{~m}$ in the $P 2$ polder. The $P 1$ polder low outlet dimensions (the inside diameter of outlet pipeline of a round shape) $d=200 \mathrm{~mm}$, there is a possibility of choice from $d=200,300$, 400, 500 or $600 \mathrm{~mm}$ for the $P 2$ polder.

\section{Results and discussion}

The model function and behaviour were examined first in relation to the project research objectives. Then the possibilities of experimentation on the model of the designed system were tested (Korsun et al., 2002). The optimization process was carried out with the three above listed values of admissible maximal runoff from the P2 polder and then in an experimental way with various runoffs from both catchments areas: with real runoffs derived from hundred-year rain storms for the individual variants of conservation measures in both the catchments areas, and with fictive multiples of these runoffs.. Variants with other changes in input conditions (e.g. without the polders entering the solving process) were calculated for the same reason. The results of these solutions are not listed here. Optimal solutions of variants No. 1, 3 and 5 correspond with the real state of the input conditions. These solution results were derived from overland flows from the grounds and from three real values of admissible maximal runoff from the $P 2$ polder above Starovice. The results of following experiments on the optimization model have led to a number of interesting findings. However, the most important finding is the fact that the experimental locality can be protected as required without any interference into plant production conditions, i.e. without any (on site) economic loss on the produce only by conservation measures themselves: by draining overland and hypodermic runoffs through contour furrows and channels in the $P 2$ polder. This protective system design is valid only provided the applied optimization criterion is kept. The resulting design can be different in the case of any change to the criterion (e.g. the changes in the weights of the three used partial criteria) or in case of the application of a different criterion.

\section{Conclusion}

The results of the practical application of the optimization procedure in designing terraces and retention reservoirs within integrated territory protection verify its functionality and applicability. In cases when it is not clear in advance which of the potential torrential rainfall could be the most dangerous, the model will provide solutions with all chosen rainfalls types for the result to comply with the territory protection requirements.

The created model can be used to find either one optimal solution or, in case it is necessary to verify the position of the optimal solutions with the changes of some input conditions and requirements, more times in more versions with variables and coefficients modified by these changes. The possibility of multiple application of this model and to obtain a whole set of 
optimal solutions visualises much better the character and behaviour of the designed system in reactions to modifications of the input conditions and requirements and thus enables to improve significantly the process of making decisions about the design final shape.

A great advantage of the model lies in the general formulation of its components - partial models of conservation measures at individual sites of the experimental locality, watercourse and reservoir. This should enable its problem-free application for optimization design of integrated territory protection under any conditions and at any site

\section{Author details}

Miroslav Dumbrovsky* and Svatopluk Korsuň

*Address all correspondence to: dumbrovsky.m@fce.vutbr.cz

Brno University of Technology, Faculty of Civil Engineering, Department of Landscape Water Management, Czech Republic

\section{References}

[1] Benedini, M. (1988). Developments and possibilities of optimisation models. Agric. Water Manag., 13, 329-358.

[2] Dumbrovský, M., et al. (2003). Optimisation of the system of soil and water conservation for runoff minimizing in certain watershed in the process of land consolidation (in Czech). Final research report, NAZV-QC1292, VÚMOP, Praha.

[3] Charamza, P., et al. (1993). Modelling system GAMS (in Czech). MFF UK, Praha.

[4] Korsuň, S., et al. (2002). Creating and verification of the model for optimisation of soil and water conservation (in Czech). Final research report, A01-NAZV-QC1292, FAST VUT, Brno.

[5] Kos, Z. (1992). Water management systems and their mathematical models during climate changes (in Czech). Vod. Hosp., 7, 211-216.

[6] Major, D. C., Lenton, R. L., et al. (1979). Applied water resource systems planning. . Prentice- Hall Inter., Inc., London.

[7] Onta, P. R., Gupta, A. D., \& Harboe, R. (1991). Multistep planning model for conjunctive use of surface and groundwater resources. Jour. Water Res. Plan. Manag., 6, 662-678.

[8] Patera, A., Váška, J., Zezulák, J., Eliáš, V., Korsuň, S., et al. (2002). Floods: prognosis, water streams and landscape (in Czech). ČVUT / ČVVS, Praha. 